\title{
Osteoporosis knowledge among female adolescents in Egypt
}

\author{
Yosria El-Said Hossien ${ }^{1}$, Hanan M. M. Tork², Amirat Ali El-Sabeely ${ }^{2}$ \\ ${ }^{1}$ Department of Community Health Nursing, Faculty of Nursing, El-Minia University, Egypt \\ ${ }^{2}$ Department of Pediatric Health Nursing, Faculty of Nursing, Zagazig University, Egypt
}

\section{Email address:}

Yosria1968@yahoo.com (Y. El-Said Hossien), hotork@zu.edu.eg (H. M. M. Tork), amirat_2012@yahoo.com (A. A. El-Sabeely)

\section{To cite this article:}

Yosria El-Said Hossien, Hanan M. M. Tork, Amirat Ali El-Sabeely. Osteoporosis Knowledge among Female Adolescents in Egypt. American Journal of Nursing Science. Vol. 3, No. 2, 2014, pp. 13-17. doi: 10.11648/j.ajns.20140302.11

\begin{abstract}
Osteoporosis is a growing chronic health problem that could result in mortalities and poor living quality. Although osteoporosis is a preventable disease affecting millions of people, the public awareness remains low and the most effective prevention of this disease is founded during childhood and adolescence when the prevention is actually the easiest. Aim: The current study assessed osteoporosis knowledge among female adolescents students in selected secondary school at El-Minia, Egypt. Methods: Information was gathered through across-sectional survey. Self-administered questionnaire consisted of 58 items assessing knowledge regarding osteoporosis was administered to one hundred and twelve female adolescent aged 15-18 years in one secondary school. Descriptive statistics was used to analyze the data. Results: Regarding knowledge of the studied sample about osteoporosis, it was found that $38.4 \%$ of the studied sample didn't know the meaning of osteoporosis, more over $75.9 \%$ of them didn't know what to do in the case of osteoporosis. Majority of the studied sample $(90.2 \%)$ mentioned exposure to sunlight as one of the preventive measures from osteoporosis. Conclusion: The present study revealed lack of awareness about osteoporosis among female adolescent, hence the findings highlight the need for educational interventions to enhance female adolescents' knowledge about osteoporosis.
\end{abstract}

Keywords: Osteoporosis, Female Adolescent, Knowledge, Egypt

\section{Introduction}

Osteoporosis is a major public health problem [1], which affects millions of people around the world and its frequency increases by age [2]. Osteoporosis characterized by reduced bone mass/density and micro-architectural deterioration of bone tissue [3]. The perception that osteoporosis is an older person's disease is an erroneous one. Osteoporosis does not discriminate by age; in fact, it is a geriatric disease with an adolescent onset. During childhood and adolescence, much more bone is deposited than withdrawn, so the skeleton grows in both size and density. Up to 90 percent of peak bone mass is acquired by age 18 in girls and by age 20 in boys, which makes youth the best time to "invest" in one's bone health [4]. Currently, Osteoporosis among the top five conditions causing disability and prolonged hospital stay for older people and from an economic perspective; the most cost approach is to focus on primary prevention via education, so the nurses often have the responsibility of providing such educational programs [5]. Constructed bone mineral density charts for
Egyptian women showed that they have a lower bone mineral density compared to their western counterparts [6]. According to the recent International Osteoporosis Foundation (IOF) report, $28.4 \%$ of postmenopausal women in Egypt are estimated to have Osteoporosis [7,8]. Although genetic factors (e.g. age, race, family history, and gender) are major determinants of peak bone mass and subsequent bone status, Osteoporosis is one of the diseases which are influenced by nutrition and lifestyle; it is preventable by means of adequate nutrition and sufficient physical activity [9]. Because lifestyle practices formed early in life and may be carried into adulthood, there is an immediate need to increase osteoporosis awareness and subsequent beliefs, not only in older women, but also in younger women $[10,11]$.

Osteoporosis includes several controllable and uncontrollable risk factors; the controllable risk factors (environmental) include low activity level, sedentary lifestyle over many years, smoking, alcohol abuse and inadequate diet including eating disorder, low calcium intake, low vitamin D 
intake and excessive consumption of soft drinks. Caffeine use of more than three cups of coffee every day might increase calcium excretion in the urine and it affects bone health. Whilst the uncontrollable factors include gender, family history, ethnicity and race, advancing age, postmenopausal status and body frame size [12].

During adolescence, a human's bone structure becomes strong and an adequate bone mass is increased. During childbearing period, women have maintained a certain amount of bone mass due to production of Estrogen hormone which protect them against bone loss. However after menopause, the ovaries discontinue to product estrogen. Women's estrogen levels decrease dramatically at menopause. Therefore the osteoporosis risk factors for women are irregular menstruation period, amenorrhea, early menopause, and reduced estrogen after menopause [13]. Achieving a higher peak bone mass through exercise and proper nutrition during adolescence is important for the prevention of osteoporosis, in addition, exercise and nutrition throughout the rest of the life delays bone degeneration. Jogging, walking, or stair climbing at $70-90 \%$ of maximum effort three times per week, along with $1,500 \mathrm{mg}$ of calcium per day, increased bone density of the lumbar (lower) spine by $5 \%$ over nine months. Individuals already diagnosed with osteopenia or osteoporosis should discuss their exercise program with their physician to avoid fractures [14]. Based on recent research, considerable number of adult males and females are unaware about osteoporosis, which indicated that there is deficiency in knowledge and poor application of the preventive actions; therefore, health education is needed to improve awareness and motivating healthy behaviours [15]. Early assessment and prevention programs should start at an early age to avoid the behavioral risk factors [16]. Effective community-based educational programs proved to have profound effect on improvement of knowledge and health behavior related to osteoporosis and its care [17].

\subsection{Significance of the Study}

Osteoporosis is a significant global public health issue, expected to affect more people worldwide than ever by 2050. It is no longer confined to the growing older population but has implications for all age groups. Public awareness of osteoporosis remains low, especially in developing countries. Health education have been shown to be effective in improving knowledge and awareness among the public and schools which can be one of the best venues for increasing knowledge of osteoporosis and inducing lasting behavioral change during adolescence; the period of peak bone density. In Egypt, there is scarcity of local studies which discuss the level of awareness toward osteoporosis in both females and males members, therefore the present study aimed to assess osteoporosis knowledge among female adolescents in El-Minia governorate, Egypt.

\section{Subjects and Method}

Descriptive design was utilized in this study, which conducted among convenience sample of one hundred twelve female adolescents in one secondary school in El-Minia.

\subsection{Tool of the Study}

The questionnaire was developed by the researchers based on reviewing the literature, it consisted of 58 questions; covering four parts; the first part (4 questions) related to social and personal characteristics of the study sample (age, residence, marital status, and ways of travelling to the school). The second part (8 questions) related to disease and family history, the third part (35 questions) included knowledge about osteoporosis. The fourth part (11 questions) included student's practices toward osteoporosis.

\subsection{Data Collection}

Prior to data collection, the necessary approval consent was secured from the director of El-Minia secondary school In addition, the purpose of the study was explained to students and their agreement was obtained. The time required to complete the questionnaire was about 20 to 30 minutes. Data was collected from November 2012 to February 2013 though structured interview, the researcher went to the secondary school two times per week (Monday and Wednesday) and each participant interviewed individually to provide more explanation and answer their questions.

\subsection{Statistical Analysis}

Data entry and analysis were done using the statistical software program SPSS version 16. The data were presented in the form of percentages and mean \pm standard deviation.

\section{Results}

Out of 150 female adolescents, who accepted to participate in the study, 112 completed the questionnaire (74.7 \% response rate). The characteristics of the participants were shown in table (1). The mean age of the participants was $17.2 \pm 0.7$ years and the majority of them $(91.9 \%)$ their age ranged from 17 to 18 years. Regarding their residence, more than three quarters of the studied sample were from rural area $(76.8 \%)$ and most of them $(98.2 \%)$ were single and travelling to the school by bus/car $(90.2 \%)$. Regards to participant's family history of osteoporosis, table (2) demonstrates that the highest percentage of the studied sample $(90.2 \%)$ had no family history of the disease. More than three quarters of the sample $(78.6 \%)$ had no inflammation in the joints and only $34.8 \%$ had difficulty in walking. As well as more than half $(52.7 \%)$ of the studied sample had no low back pain and 
$72.3 \%$ had weakness in their muscles. As regards risk factors for developing osteoporosis, the percentage of students' knowledge about osteoporosis risk factors is shown in figure (1).

Table 1. Demographic characteristics of the studied sample $(N=112)$.

\begin{tabular}{lll}
\hline Characteristics & Frequency & Percentage \\
\hline Age ( years): & 10 & \\
$15-<17$ & 102 & 9.9 \\
$17-18$ & $(15-18)$ & \\
Range & $17.2 \pm 0.7$ & \\
Mean \pm SD & & \\
Residence : & 86 & 76.8 \\
Rural & 26 & 23.2 \\
Urban & & \\
Marital status : & 110 & 98.2 \\
Single & 2 & 1.8 \\
Married & & \\
Ways of travelling to the school : & 101 & 90.2 \\
By bus / car & 11 & 9.8 \\
On feet &
\end{tabular}

Being a female and advanced age were the most common identified risk factors $(48.4 \%$ and $29.8 \%$ respectively). Low calcium intake and early menopause were confirmed by $5.7 \%$ and $5.4 \%$ as risk factors. Excess in drinking of soft drinks was recognized by only $1.8 \%$ of the respondents, while $8.9 \%$ of students didn't know the risk factors for developing osteoporosis.

Table 2. Participant's family history of Osteoporosis $(N=112)$.

\begin{tabular}{lll}
\hline Variable & No & \% \\
\hline Family history of Osteoporosis & & \\
Yes & 11 & 9.8 \\
No & 101 & 90.2 \\
Have you had inflammation in the joints & & \\
Yes & 24 & 21.4 \\
No & 88 & 78.6 \\
Have you had difficulty in walking & & \\
Yes & 39 & 34.8 \\
No & 73 & 65.2 \\
Have you had lower back pain & & \\
Yes & 53 & 47.3 \\
No & 59 & 52.7 \\
Have you had muscle's weakness & & \\
Yes & 31 & 27.7 \\
No & 81 & 72.3 \\
\hline
\end{tabular}

Most of participants identified regular exercise and exposure to sun light as preventive measures for osteoporosis (94.6\% \& 90.2\% respectively), meanwhile only $7.1 \%$ could identify eating diet rich in calcium and vitamin (D) as a preventive measure (table 3). Knowledge and practices of physical activities are illustrated in table (4), one hundred and six students (94.6\%) were aware of the benefits of exercise in preventing osteoporosis, yet $58 \%$

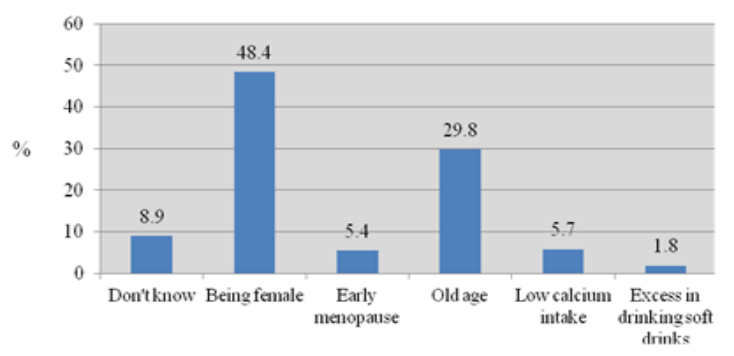

Fig. 1. Students' knowledge regarding risk factors for osteoporosis.

Were engaged in some sort of physical activity not on a regular basis as they reported. Concerning knowledge of the studied sample about osteoporosis; it was found that $38.4 \%$ of the studied sample had no knowledge regarding the meaning of osteoporosis, more over $75.9 \%$ of them didn't know the proper action in case of osteoporosis and only $46.4 \%$ of them stated that female more susceptible to osteoporosis (table 5).

Table 3. Frequency and percentage of students who identified preventive measures for osteoporosis correctly.

\begin{tabular}{lcc}
\hline \multicolumn{1}{c}{ preventive measures } & No & \% \\
\hline Exposure to sun light & 101 & 90.2 \\
Eating diet rich in calcium \& vitamin D & 8 & 7.1 \\
Regular exercise & 106 & 94.6 \\
Limit the intake of tea and coffee & 6 & 5.4 \\
\hline
\end{tabular}

Table 4. Participants' knowledge and practices of physical exercise.

\begin{tabular}{lll}
\hline Item & No & \% \\
\hline Regular exercise can protect against osteoporosis & & \\
Yes & 106 & 94.6 \\
No & 6 & 5.4 \\
Do you practice physical exercise & & \\
Yes & 65 & 58 \\
No & 47 & 42 \\
If yes, sort of exercise & & \\
Walking & 61 & 54.5 \\
Running & 1 & 0.9 \\
Sports training & 2 & 1.8 \\
Volley ball & 1 & 0.9 \\
Times/wk (3 times) & 39 & 34.8 \\
Duration (15-30 minutes/time) & 51 & 45.6 \\
\hline
\end{tabular}

Table 5. Knowledge of participants related to Osteoporosis.

\begin{tabular}{lll}
\hline Item & No. & \% \\
\hline Meaning of Osteoporosis & & \\
Don't know & 43 & 38.4 \\
a medical condition caused by lack of bone & 41 & 36.6 \\
density & & \\
Bony protrusion appear in certain places & 2 & 1.8 \\
Inability to walk & 10 & 8.9 \\
Bone atrophy affects the body & 16 & 14.3 \\
Proper action in case of osteoporosis & & \\
Don't know & 85 & 75.9 \\
Taking calcium and avoid taking soft drinks & 14 & 12.5 \\
Follow up with doctors & 9 & 8.0 \\
Bed rest & 3 & 2.7 \\
Taking calcium and vitamins & 1 & 0.9 \\
Most susceptible gender to osteoporosis & & \\
Don't know & 57 & 50.9 \\
Male & 3 & 2.7 \\
\hline
\end{tabular}




\begin{tabular}{lll}
\hline Item & No. & \% \\
\hline Female & 52 & 46.4 \\
Bones more likely to break & & \\
Don't know & 49 & 43.8 \\
Pelvis & 13 & 11.6 \\
Thigh & 13 & 11.6 \\
Leg & 24 & 21.5 \\
Wrist & 13 & 11.6 \\
Do osteoporosis occurs suddenly & & \\
Yes & 18 & 16.1 \\
No & 94 & 83.9 \\
Age more affected with osteoporosis & & \\
Don't know & 28 & 25.0 \\
Children & 11 & 9.8 \\
Old age & 48 & 42.9 \\
Middle age & 3 & 2.7 \\
At any age & 22 & 19.6 \\
\hline
\end{tabular}

Regarding to knowledge of the studied sample about foods that rich in calcium, it was found that the majority of the studied sample $(99.1 \%)$ stated that milk is rich in calcium and $76.8 \%$ of them recommended its daily consumption. In addition, $28.6 \%$ of participants reported poultry meat as a rich source for calcium and $50.9 \%$ of them recommended its daily consumption (table 6).

Table 6. Knowledge of participants related to nutrition.

\begin{tabular}{lll}
\hline Variable & No & \% \\
\hline Food identified by participants as a rich source of calcium \\
Dairy products: & \multicolumn{2}{l}{} \\
milk & 111 & 99.1 \\
Yogurt & 1 & 0.9 \\
Recommended consumption & & \\
Monthly & 13 & 11.6 \\
Weekly & 13 & 11.6 \\
Daily & 86 & 76.8 \\
Meat and fish & & \\
Poultry meat (chicken meat) & 32 & 28.6 \\
Liver & 8 & 7.1 \\
Domestic fish & 18 & 16.1 \\
Sardines & 9 & 8.0 \\
Eggs & 45 & 40.2 \\
Recommended consumption & & \\
Monthly & 9 & 8.0 \\
Weekly & 46 & 41.1 \\
Daily & 57 & 50.9 \\
Other food & & 67.0 \\
Beans & 75 & 26.8 \\
vegetables & 30 &
\end{tabular}

\section{Discussion}

Osteoporosis has recently been recognized as a major public health problem $[1,18]$, it is no longer confined to the growing older population but has implications for all age groups [19]. Hence increasing knowledge of osteoporosis should be a priority for future intervention programs in order to promote specific behavioral strategies for osteoporosis prevention [20]. The purpose of this study was to assess osteoporosis knowledge among female adolescents students in secondary school in El-Minia, Egypt. The present study revealed that more than one third of the participants had known the meaning of osteoporosis, the same results were obtained from the Turkish women by Gemalmas \& Oge (2008) [21] and also from Taiwan young adult women by Chang (2006-b) [22]. On the other hand higher proportions were obtained by Alexandraki et al. (2007) [20] and Yeab et al. (2010) [23], who conducted their studies in Malaysia and Greece respectively.

Regarding the risk factors for developing osteoporosis, results of the presents study revealed that the studied sample were aware of the risk factors and this agreed with National osteoporosis foundation [12] which mentioned that risk factors that increase or cause osteoporosis include gender, family history, advancing age , post menopausal status and excess in soft drinks. According to Chan, (2006) [5], exercise and walking programs can help build stronger bones and muscles and can be used to increase strength, flexibility and balance. Based on the findings of the current research, students knew that regular exercise can protect against osteoporosis, but this knowledge does not translate to practices; nearly one-half of the students were exercising at a minimal level and not on regular basis.

When identifying good sources of calcium, the studied sample answered buffalo milk $(99.1 \%)$ as dairy products and this agreed with the result of Fok et al. [24] who mentioned that people can get calcium from milk products and calcium rich diet.

The majority of the studied sample (90. $2 \%$ ) knew that exposure to the sun is good for bone and this agreed with Insel et al. [25] who found that usually 10-15 minutes exposure of the hands, arms and face two or three times a week is enough to satisfy the body's vitamin D requirement. In order to meet the challenges and threats of osteoporosis, prevention efforts need to be geared to young girls and women. In this regards, defective knowledge about preventive measures for osteoporosis was observed in this study as regards to eating diet rich in calcium \& vitamin D and also regarding limitation of the intake of tea and coffee. This was in an agreement with Cadarette et al. [26] from Canada who reported significant knowledge deficit in the areas of osteoporosis consequences and prevention.

\section{Conclusion and recommendations}

In conclusion, the present study reveals lack of awareness about osteoporosis among female adolescent, so the study could serve as a stimulant for further researchers to assess knowledge and other practices toward preventive measures among other age groups. Ministry of Education should be involved in health education about osteoporosis and its related factors in schools or even could provide educational program via their curriculum to improve the awareness of this disease among students and thus ensuring that they received accurate information. The challenge remains in turning knowledge gained from health education into lifelong practices and adopting new health behaviours. Further researches geared toward the follow-up of attained knowledge and behavioural change over time is needed. 


\section{Ethical Considerations}

Ethical approval was obtained from the administration of educational region of the participated school and the confidentiality of information was maintained by assigning identification numbers. The participating students did get written and oral information before the beginning of the study. They were informed about the right to quit at any time without the need for an explanation and without any consequences for them. The participants gave written informed consent before entering the study.

\section{Acknowledgment}

The authors are very much grateful to all participants of the study for their kind cooperation.

\section{References}

[1] Riaz M, Patel J, Tariq M, Khan MS, Zuberi L, \& Abid N. (2008) Knowledge about Osteoporosis among healthy women attending a tertiary care hospital. Journal of the Pakistan Medical Association 58, 190-194.

[2] Jalili Z, Nakhaee N, Askaril R, \& Sharifi V. (2007) Knowledge, attitude and preventive Practice of women concerning osteoporosis. Iranian Journal of Public Health 36, $19-24$.

[3] Vaytrisalova M, Kubena A, Vleek V, Palicka T, Hala, T \& Pavelka K (2007) Knowledge of osteoporosis correlated with hormone therapy use and health status. Maturitas 56(1): 21-29.

[4] Wahba SA, Abd El-Shaheed A, Tawheed MS, Mekkawy AA, Arrafa AM (2010) Osteoporosis knowledge, beliefs, and behaviors among Egyptian female students. Journal of the Arab Society for Medical Research 5(2): 173-180.

[5] Chan MF. (2006) Osteoporosis prevention education programme for women. Journal of advanced nursing 54(2), 159-170.

[6] Sallam H, Galal AF \& Rashed A. (2006) Menopause in Egypt: past and present perspectives. Climacteric 9(6): 421-429.

[7] International osteoporosis foundation (2010) Available at http://www.iofbonehealth.org/ (accessed 13 Feb. 2013).

[8] Taha M. (2011) Prevalence of osteoporosis in Middle East: systemic literature review. 10th ECOO, April 2011. Available at http://www.scribd.com/doc (accessed 20 June 2012).

[9] Stransky M, \& Rysava L. (2009) Nutrition as prevention and treatment of Osteoporosis. Physiol Res. 58:Suppl 1:S7-S11.

[10] Siegrist M. (2008) Role of physical activity in the prevention of osteoporosis. Med Monatsschr Pharm, Jul;31(7):259-64.

[11] Miura S, Yagi M, Saavedra OL, Yamamoto S. (2010) Sociodemographic variation in knowledge of osteoporosis and locally available calcium-rich foods among urban women living in Davao, Philippines. Health Care Women Inter. 31(5):378-401.

[12] National osteoporosis foundation (2011) Available at. http://www.nof.org/node/150 (accessed 11 January 2013).

[13] Rodzik E. (2008) Osteoporosis education in college- age of women. Eastern Michigan University Masters Theses.

[14] Osteoporosis Australia (2011) Available at http://www.osteoprosis.org.au (accessed 8 December 2012).

[15] Barzanji AT, Alamri FA, \& Mohamed AG (2013) Osteoporosis: A Study of Knowledge, Attitude and Practice among adults in Riyadh, Saudi Arabia. J Community Health, 38:1098-1105.

[16] Cline RR \& Worley MM, (2006) Osteoporosis health beliefs and self-care behaviors: an exploratory investigation. JAM pharm Assoc, 46(3): 356-364.

[17] Chang SF, (2006-a) Knowledge, health belifes and behaviours in first - degree relatives of women suffering from osteoporosis. J Clin Nurs, 15(2):227-229.

[18] Kustal YG, Atalay A, Arslan S, Basaran F, Canturk A, Cindas M, Eryavuz J \& Sindel K, (2005) Awareness of osteoporotic patients. Osteoporor Int 16(2):128-33.

[19] Hannon C. (2007) A survey of nurse's and midwives knowledge of risks and life style factors associated with osteoporosis. vol. 18 suppl.3 osteoporosis international, 265: $7 \mathrm{~A}$.

[20] Alexandraki KI, Syrion V, Ziakas NV, Piperi E, Kavoulaki I \& Korres E (2007) The knowledge of osteoporosis risk factors in a Greek female population. Maturitas. 59(1):38-45.

[21] Gemalmaz A, \& Oge A. (2008) Knoweldge and awareness about osteoporosis and its related factors among rural Turkish women. Clin Rheumatol. 27(6):723-8.

[22] Chang S.F. (2006-b) "A cross-sectional survey of calcium intake in relation to knowledge of osteoporosis and beliefs in young adult women." International Journal of Nursing Practice 12: 21-27.

[23] Yeab SS, GohEM, Das Gupta E. (2010) Knowledge about osteoporosis in Malaysia population. Asia Pac J Public Health 22(2): 233-410.

[24] Fok MW, Leung HB, Lee WM. (2008) Osteoporosis: public awareness, commitment, and perspective. Hong Kong Med J.14(3):203-8.

[25] Insel P, Turner RE, \& Ross D. (2004) Nutrition, 2nd edn. Jones \& Bartlett Publishers, Sudbury, Massachuselt.

[26] Cadarette SM, Gignac MA, Beaton DE, Jaglal SB, \& Hawker GA. (2007) Psychometric properties of the osteoporosis and you, questionnaire: osteoporosis knowledge deficits among elder community-dwelling women. Osteoporosis Int., 18(7): 981-989. 